\title{
Research on Decision-making of PPP Project Franchise in Large-scale Stadiums:A system dynamics application
}

\author{
Su Dan ${ }^{1, \text { a, * }, \text { Liu Yisheng }}{ }^{1, b}$ \\ ${ }^{1}$ School of Economics and Management, Beijing Jiaotong University, Beijing 100044 ,China; \\ adannasu93@126.com, ${ }^{\text {b} 16113148 @ b j t u . e d u . c n ~}$
}

Keywords: Large-scale stadiums, PPP, Franchising, System Dynamics.

\begin{abstract}
In order to meet the people's growing demand for sports products and solve the contradiction between the increasing investment demand of private capital and the deficit of government finance, the construction of large-scale sports venues for PPP model has become the trend. However, the proceeds of the PPP project in the operation process and the determination of the franchise period are the key to the success of the project. The franchise decision model is constructed, based on the system dynamics and net present value method, and the minimum value of the acceptable franchise period is calculated from the angle of social capital. Taking the operation data of a large stadium as an example, the influence of different profit on the decision-making of franchise is discussed, which can provide reference for the franchise decision-making between the government and social capital investors.
\end{abstract}

\section{Introduction}

Large-scale stadiums are versatile, It is not only the hardware facilities for the sports' development (Du Zechao,2012), but also an important carrier to enhance the people's life of spiritual civilization (Deng Yun, 2015). According to China's sixth national sports venues census data, as of the end of 2013, the total number of sports venues in China was 1,694,600, compared with the end of 2003(85.01 million) increased by 99.34\%. On October 2, 2014, the State Council issued the "A number of opinions of State Council on accelerating the development of sports industry to promote sports consumption " (Guo Fa [2014] No.46), the document proposed that China will reach the target in 2025 that the per capital sports venues from $1.46 \mathrm{~m}^{2}$ upgrade to $2 \mathrm{~m}^{2}$, it can be seen in the next ten years, the needs of China's large-scale sports venues construction are still high. However, there are still some problems with the development of large-scale stadium projects, on the one hand, the investment of large-scale stadium is huge; On the other hand, the period of large-scale stadium construction and payback is long, the risk of operating loss is huge with a lot of uncertainty and so on. PPP (Public-Private Partnership), as an innovative project delivery model, is favored by governments because of its advantages in improving infrastructure management and public service quality, encouraging innovation and optimizing risk transfer (Chen et al., 2009).

Sun Guixiang, Du Jing (2009) believe that the project return is mainly affected by a comprehensive impact which involved the franchise period, the level of benchmark income and capital flow. Only if government departments and the private sector to reach a consensus in these three areas that we may have a successful PPP project construction. In the operation of large-scale stadium PPP project, a reasonable determination of the franchise period is an important factor of determining the success of the project. As one of the core terms of the PPP project, the determination of the franchise period reflects the game between the government and the private sector, which is the key to determining whether the PPP project can achieve "win-win". Therefore, the franchise decision-making is the focus on bilateral contract negotiations, but also on the PPP research hot spots. In the domestic and foreign literatures, there are several ways to determine the franchise period of PPP project: empirical analogy, net present value method, game method, Monte Carlo simulation method and system dynamics method. 
Based on the traditional net present value method, Li Qiming (2000) first incorporated the government interest into the decision-making model, taking into account the parameters that affect the duration of the franchise, including the pre-transfer period, the construction period and the operation period. Li Mingxiao and Ye Wan (2016) follow the theory of net present value method, based on the analysis of government financial affordability, analyze the factors such as financial payment ability, social capital investment expectation and project profit level, and then on the basis of balanced consideration of the interests of both government departments and private enterprises to build a concession period decision model to solve the best concession period interval. Yang et al. (2003), based on the assumption that construction costs are negatively correlated with annual maintenance costs, consider the decision-making process of the concession period as an information dynamic game process, the franchise period is used as the decision variable of the government, and the game model between the government and the project company is established. Through the game analysis, the optimal decision model of the concession period under the fixed period of operation is obtained. Michael \& Charles (2003) applied the real option theory to propose a calculation model for the franchise period. Zhang and Abourizk (2006) used the Monte Carlo simulation to solve the project's franchise period by using the key variables that affected the franchise period as simulated variables.

System dynamics method is based on feedback control theory, take computer simulation technology as a means, through the establishment of system dynamics model to study and solve complex practical problems of effective methods. It appeared in 1956, the founder is Professor Forrest from the Massachusetts Institute of Technology. Found at the beginning called "industrial dynamics", mainly used in business management, and later gradually applied to various fields, hence the name "system dynamics". Zhang Baochuang (2016) translates the net present value method into the form of opportunity cost, and uses the system dynamics model to determine the acceptable franchise period. The decision-making period of the PPP project in large-scale stadiums involves the construction of cost, operating costs, operating income and other uncertain variables, and there are non-linear relationship between these variables, so we can use the system dynamics. Taking into account the project affected the franchise period of multiple factors and their relationship, in the case of insufficient data can still be simulated experiments in order to understand the mechanism of action between the elements of the project franchise. Application system dynamics can not only reflect the relationship between the various factors that affect the franchise period in the large-scale stadium PPP project, but also can dynamically simulate the whole operation through the model and change the relevant parameters Measure the effect of the change in the variable on the overall system, and in the case of insufficient data, it is still possible to perform simulation experiments to understand the mechanism of action between the project franchise elements.

This paper stand in the perspective of the private sector, based on net present value method, combing the factors that affect the net present value of the private sector in the operation processes after the big stadiums built in PPP projects, and analyze the relationship between these factors. And calculate the minimum value of the franchise period that the private sector can accept according to the actual case data, and verify the feasibility of the model.

\section{Model building}

\subsection{Causal analysis of Variables}

The result is a time-point by using the traditional NPV method to solve the problem of franchise period, however, through the use of system dynamics method, can be very convenient to make sensitivity analysis for the uncertainties, and then obtain a range of values, so that make decisions more scientific. The starting point of the model is defined as the initial of operation after the end of the construction period, By combing the existing research results, it is concluded that the main influencing factors of the franchise period of PPP projects in large stadiums(As shown in Figure 1). The setting of the franchise period is closely related to the profit of the franchise period, the present value of the total cost of private capital mainly involves three parts: operating cost, tax and 
construction cost, while the is mainly based on operating income, the influencing factors are also affected by their influence factors. Using Vensim software to establish the causal relationship between the elements of the project revenue system during the franchise period (As shown in Figure 1 ), which pave the way for the next step, Where the arrow with "+" indicates that the arrow variable is the same as the change in the arrow tail variable, and the arrow with "-" indicates that the arrow variable is the opposite of the change in the arrow tail variable.

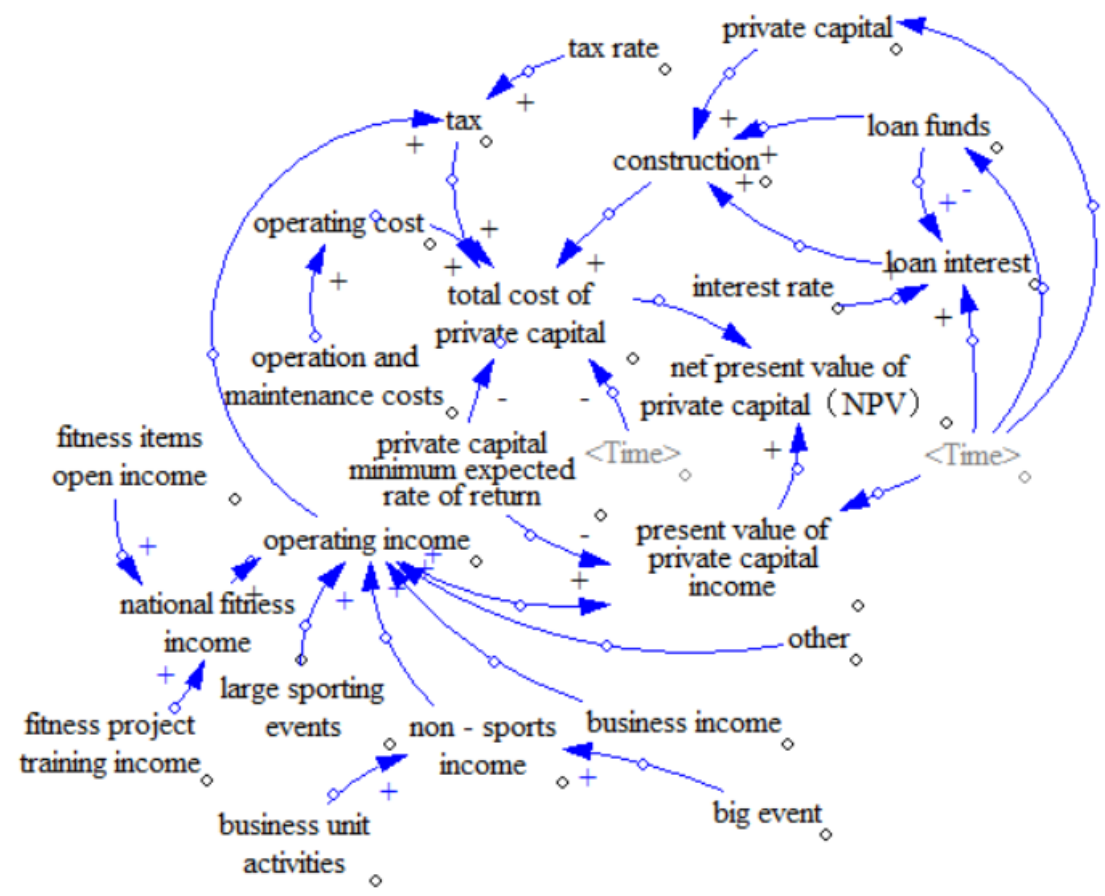

Fig.1 The causal relationship between the proceeds of the PPP project during the franchise period of the large stadium

\subsection{Model establishment}

The fundamental principle of determining the minimum operating time from the perspective of private capital continues to follow the traditional net present value method as show in (1). In the system dynamics, there are several ways to represent the causal relationship and feedback loop inside the system, In this paper, I pick up the method of stock-flow, and use Vensim software as a modeling tool. In the stock-flow method, the following types of variables are mainly included: Box variable-level(variables with system cumulative effects), rate variables (variables that describe the rate of change of the cumulative effect of the system), constants (the amount that does not vary with time), Exogenous variables (variables determined by the external environment in which the system is located, which can affect the endogenous variables of the system, but are not disturbed by the above endogenous variables), as shown in Fig.2.

$$
\mathrm{NPV}=\sum_{0}^{T} \frac{C I_{t}-C O_{t}}{(1+i)^{t}} \geq 0 \quad(t=0,1,2, \ldots, T)
$$

Fig.2 Horizontal and Rate Variables

In order to determine the lower limit acceptable to private capital franchise, it is necessary to follow the top-down decomposition principle, and construct a private capital franchise decision model by decomposing and combining. According to the causal relationship in Figure 1, in Vensim draw a flow chart of large-scale stadium PPP project's revenue during the franchise period, as shown in Figure 3. 


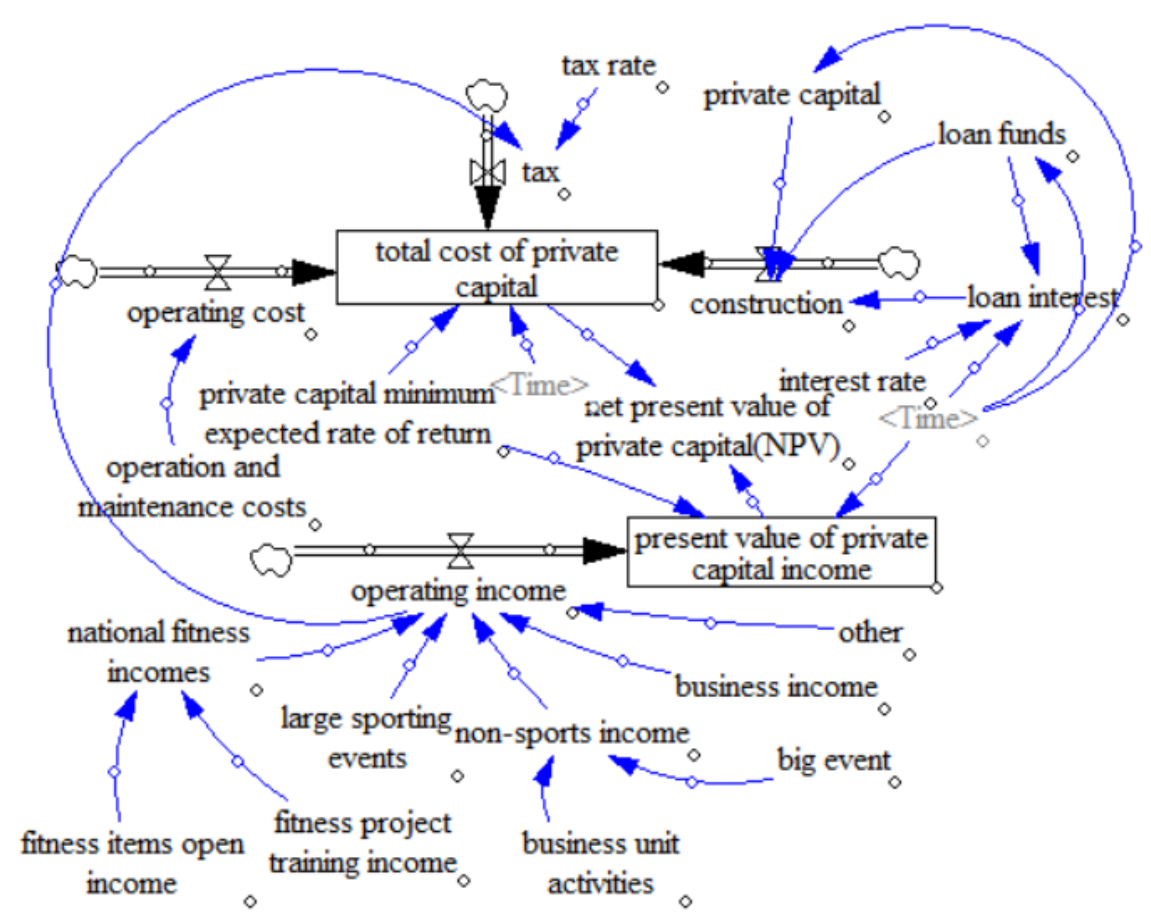

Fig.3 Flow chart of large-scale stadium PPP project during the franchise period

(1) According to Equation 1, the net present value (NPV) of private capital is decomposed into the present value of the total income $\left(\sum_{0}^{T} \frac{C I_{t}}{(1+i)^{\mathrm{t}}}\right)$ and the present value of the total $\operatorname{cost}\left(\sum_{0}^{T} \frac{C O_{t}}{(1+i)^{\mathrm{t}}}\right)$. That is to say, net present value of private capital = total present value of private capital - total cost of private capital present value.

(2) The present value of the total income of private capital is the present value of the sum of the annual income of the private capital during the franchise period in accordance with the minimum expected rate of return on private capital. That is to say, private capital total income present value $=$ (operating income) / $(1+\text { private capital minimum expected rate of return })^{\text {Time. }}$

(3) The total present value of private capital is the sum of the annual costs of private capital during the franchise period and is converted into the present value at the minimum expected rate of return on private capital. That is to say, private capital total income present value $=$ (construction cost + operating cost $+\operatorname{tax}) /(1+\text { private capital minimum expected rate of return })^{\text {Time. }}$

(4) Revenue refers to all income items in the operation phase of a large stadium, including: national fitness income, income from large sports events, non-sports income, business income and others. That is, operating income $=$ national fitness income + large sports events + non-sports income + business income + other.

(5) The cost of construction of private capital takes into account the capital and the loans and interest during the construction period, so the construction cost is equal to the sum of the annual payment of capital and loans (including interest). That is, construction costs $=$ capital + loan principal + loan interest, where loan interest $=$ loan principal * $(1+\text { interest rate })^{\text {Time. }}$

(6) The operating costs of large stadiums, including operating and maintenance costs, staff salaries, and overhaul fees, are not easily itemized, but are basically stable in a fixed range each year, so they are determined by inputting the basic data as a constant.

(7) The tax is the sum of all taxes, including value-added tax, income tax and all taxes. Due to the reform program to replace the business tax with a value-added tax will be expanded nationwide, so that business tax out of the stage of history, but the highway enterprises in the camp to increase the overall level of tax burden has not changed much. Business tax out of the stage of history, But the tax burden level has not changed much. That is, tax $=$ operating income $*$ tax rate.

(8) "Time" is an exogenous variable, where "Time" is the franchise period. 


\section{Case analysis and simulation}

In order to verify the validity of the model, and to describe the calculation process, a large stadium project was used as a case. However, due to incomplete data collection, so part of the operating period of the data refer to the same period of similar projects.

\subsection{Case background}

(1) Basic profile of the project

A large-scale stadium project using PPP model, and the franchise period is determined by the government and private capital. The project's construction began at the end of 2003, completed by the end of 2007, the construction period of 4 years. The project will be handed over to the government after the end of the concession period. The real data and information forming the cash flow are derived from the feasibility study report of the project, The rest of the data, partly from the actual situation of the project, some of the data that can not be obtained are come from the similar projects that in same period of time to build. After the end of the concession period, the project will be transferred to the government free of charge, the project has no surplus value.

(2) Related data

(1)Initial setting

Initial time: 1 , end time: 50 , time step: 1 , unit: year.

The end time is set to 50, because it is based on the provisions of the Gymnasium Design Code (see Table 1). Most of the stadiums are designed for a period of 100 years. If the franchise period exceeds 50, the proportion of maintenance costs may be too high to attract private capital. Therefore, the 50-year limit for the franchise period is determined.

Table 1 Years of design of the building structure(Unit: year)

\begin{tabular}{|c|c|c|c|}
\hline Building grade & Special grade & Grade A\B & Grade C \\
\hline The length of the main structure design & $>100$ & $50-100$ & $25-50$ \\
\hline
\end{tabular}

- Source: The Gymnasium Design Code

(2)Private capital operating costs

As the data in this case is difficult to obtain, reference is made to the project which has same operation period and similar scale. The data show that operating costs of 38-40 million, tentatively 38 million yuan.

(3) Construction costs

The construction costs of the case include capital, loans, loan interest and government subsidies, but because of the inability to obtain detailed repayment methods and loan interest rates and other data, so the model is simplified, one-time investment costs of 667 million yuan.

(4) Operating income

According to the data of similar projects (see Table 2), fitness project training income, business income and other data have a clear linear growth trend, so it is assumed that it will linear growth for ten years, then in a stable period. Other items of large fluctuations or growth trend is not obvious, can not be linear analysis, so take the average. 
Table 2 A large stadium 2010 - 2012 income accounting table (Unit: million)

\begin{tabular}{|c|c|c|c|c|c|c|}
\hline \multicolumn{2}{|c|}{$\begin{array}{l}\text { Time } \\
\text { Income item }\end{array}$} & 2010 & 2011 & 2012 & Mean & Image \\
\hline \multirow{2}{*}{$\begin{array}{l}\text { National } \\
\text { fitness } \\
\text { incomes }\end{array}$} & $\begin{array}{l}\text { Fitness items } \\
\text { open income }\end{array}$ & 7.6927 & 7.6993 & 6.1567 & 7.1829 & \\
\hline & $\begin{array}{l}\text { Fitness } \\
\text { project } \\
\text { training } \\
\text { income }\end{array}$ & 0.4467 & 0.7761 & 1.1670 & - & $\mathrm{y}=0.3$ \\
\hline \multicolumn{2}{|c|}{ Large sporting events } & 2.2627 & 8.6564 & 1.4143 & 4.1111 & \\
\hline \multirow{2}{*}{$\begin{array}{l}\text { Non-sports } \\
\text { income }\end{array}$} & Big event & 6.4415 & 4.7809 & 5.6274 & 5.6166 & \\
\hline & $\begin{array}{l}\text { Business unit } \\
\text { activities }\end{array}$ & 1.188 & 0.8960 & 1.4021 & 1.1606 & \\
\hline \multicolumn{2}{|c|}{ Business income } & 20.4453 & 25.2716 & 30.2530 & - & $\longrightarrow$ \\
\hline \multicolumn{2}{|c|}{ Other } & 0.3300 & 2.7516 & 7.5819 & - & $y=3.626 x$ \\
\hline
\end{tabular}

- Source: Internal data

\section{(5)Tax rate}

The tax rate is a comprehensive tax rate, which contains multiple taxes, so it is difficult to carry out accurate calculations, so refer to multi-case data, the model of the tax rate was 5.5\%.

(6) Private capital minimum expected rate of return

National Development and Reform Commission Investment Research Institute of Institutional Policy Director Wu Yaping pointed out that the user to pay the PPP project, the current stage of reasonable return on investment can be set at $7.0 \%-8.0 \%$. At present, the decline in private capital investment growth rate is more serious, so cautious choice of $7.0 \%$ as the minimum expected rate of return on private capital.

\subsection{Validity test of the model}

After the model has finished editing, it is necessary to test the validity of each formula of the model before making the simulation. Validity test including the editing logic of the formula, the publicity content and symbols of a test, if the logic barrier or symbols are not unified, Vensim software will prompt "wrong / incomplete equation", if the editor is correct, the software will prompt "equation no problem".

After repeated correction and adjustment, the model through the validity test.

\subsection{Simulation results}

By entering the above private capital data and equation into the model, the private capital required to obtain the franchise period is a minimum of 33 years, NPV graphics and detailed data are shown in Figure 4 and Figure 5: 


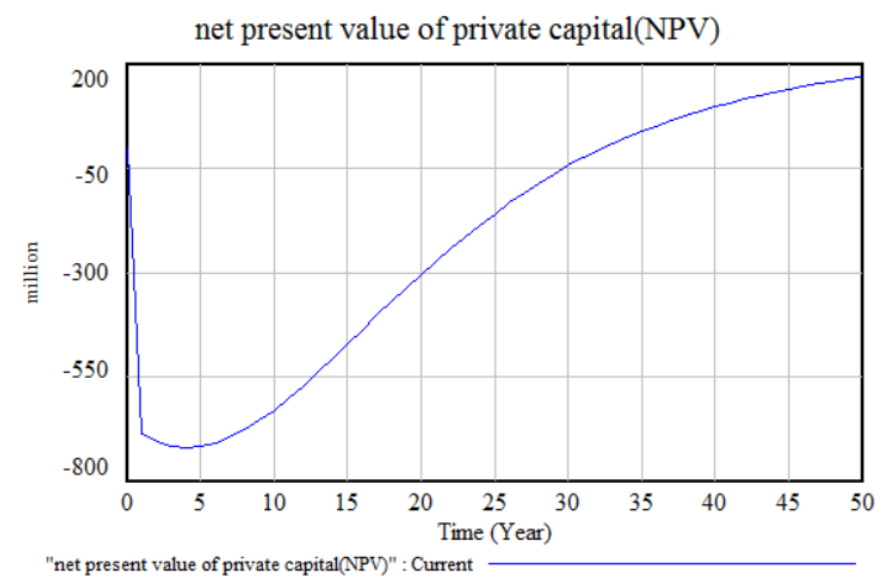

Fig.4 Net present value curve of private capital

\begin{tabular}{|c|c|c|c|c|}
\hline (Year) & 31 & 32 & 33 & 34 \\
\hline net present value of private capital(NPV)" Runs: & Current & & & \\
\hline "net present value of private capital(NP'-44.1133 & -25.3232 & -7.76245 & 8.64954 & 23.9878 \\
\hline
\end{tabular}

Fig.5 Detailed data on the net present value of private capital

In the first 32 years, the value of NPV has been negative, and the trend has decreased first and then increased to 7.7624 million. At the 33rd year NPV first appeared positive and maintained growth trend with the growth rate is declining, and gradually stabilized. Indicating that private capital began to gain profits from franchise rights from the 33rd year, so the minimum franchise required for private capital should be 33 years.

\subsection{Sensitivity analysis}

Sensitivity analysis is the study of how the uncertainty in the output of a mathematical model or system (numerical or otherwise) can be apportioned to different sources of uncertainty in its inputs. In this paper, there are several parameters that affect the length of the franchise period, and the operation cost is taken as an example to analyze the single factor sensitivity.

The data show that operating costs are between 38 and 40 million, take 38 million as the base, each time increase of 500,000 yuan and cycle 4 times, through the software to observe the changes in NPV, as shown in Table 3.

Table 3 Analysis of operating cost sensitivity(Unit: million)

\begin{tabular}{|c|c|c|c|c|c|}
\hline Operating costs & 38 & 38.5 & 39 & 39.5 & 40 \\
\hline Minimum franchise period of private capital & 33 & 33 & 34 & 34 & 35 \\
\hline
\end{tabular}

As can be seen from Table 3, the impact of operating costs on the minimum franchise period of private capital is positively correlated, that is, the minimum franchise period of private capital increases with the increase in operating costs, and changes to 1 million, the minimum franchise period of private capital must change. Therefore, when calculating the franchise period with the government, the estimation of operating costs is a key parameter that needs attention.

\section{Conclusion}

In the trend of changing the mode of economic development and adjusting the economic structure, the local government revenue growth slowed down, but with the improvement of people's living standards, higher demand for sports products continue to increase. It is wise to use the PPP model to build large stadiums in the face of the contradiction that this revenue is grow slowly and the spending continues to expand. But in practice, government and private capital have a great disagreement in the franchise negotiations and there is no reasonable basis for reference. In this paper, from the perspective of private capital, through the construction of PPP large Stadium project franchise model to identify the acceptable minimum franchise period. 
(1) The system dynamics model can simulate the PPP project franchise well. Vensim software can not only reflect the relationship between the various factors intuitively, but also possible to accurately quantify the specific role of the variable in the entire model by editing the assignment or equation of the variable. In addition, you can dynamically reflect the impact of variables on the entire system, by changing the assignment, to provide users with a clearer comparative analysis;

(2) The results of the negotiations between private capital and the government about the franchise period have a direct impact on the project's earnings. This paper stands on the perspective of private capital, hoping to provide a bottom line for private capital to protect investment income. From another point of view, when private capital has a reasonable basis for reference, clear the size of the profits available from it, in turn, can also attract its investment in PPP projects;

(3) The model of this paper is still inadequate, need to be further improved. Firstly, the construction of the model simplifies the actual situation, and the fineness of the model needs to be further deepened. Secondly, there is still a lack of case data collection in this model, which leads to some deviations in the simulation results. These shortcomings need to be further considered perfect.

\section{References}

[1] Carbonara, N. Costantino, N. and Pellegrino, R. Concession period for PPPs: A win-win model for a fair risk sharing.International Journal of Project Management. 2014, 32(7): 1223-1232.

[2] Chen, C., Can the pilot BOT Project provide a template for future projects? A case study of the Chengdu No. 6 Water Plant B Project. International Journal of Project Management,2009,pp.573-583.

[3] Davidson,R.,Rogers,T.,Marketing Destinations and Venues for Conferences, Conventions and Business Events. Butterworth-Heinemann, Oxford,2006.

[4] Efficiency Unit, 2008. An Introductory Guide to Public Private Partnerships (PPPs), In: E. UNIT (Ed.), 2 ed. Efficiency Unit, Hong Kong.

[5] Liang, W., Song, X., Wang, S.. Case Study of the Bird's Nest: Risks and Opportunities in China's PPP Implementations in Major Sports Facilities (Haikou),2011.

[6] Liu, T, and Wilkinson.Large-scale public venue development and the application of PublicPrivate Partnerships (PPPs). International Journal of Project Management, 2013,32 (2014) 88-100.

[7] Ye, S. D.Tiong, R. L. K. The effect of concession period design on completion risk management of BOT projects. Construction Management and Economics, 2003, 21(5): 471-482.

[8] Zhang, X.,Win-win concession period determination methodology. Construction Engineering and Management. 2009, 135(6): 550-558.

[9] Yang Hongwei, Zhou Jing, He Jianmin.Commercial BOT project decision-making model based on game theory. Journal of Management Engineering,2003,(03): 93-95(in Chinese).

[10]Chen Huanhuan. Based on the system dynamics of highway PPP project concession pricing model. Lanzhou Jiaotong University, 2014(in Chinese).

[11]Deng Yun. PPP model of large-scale stadium project governance mechanism. Chongqing University, 2015(in Chinese).

[12] Du Zechao. Based on the PPP perspective of China's large-scale stadium construction and management system. Tianjin University, 2012(in Chinese).

[13]Huang Dawei, Lv Zhouyang. Study on the franchise period of PPP project based on guarantee option. Water Conservancy, 2016, (06): 26-29(in Chinese).

[14]LI Mingxiao, Ye Wan. Study on the Method of Determining PPP Franchise Based on Financial 
Capacity. Journal of Engineering Management,2016,(05): 66-70(in Chinese).

[15]Li Qiming, Shen Liyin. Decision-making model of concession period for infrastructure BOT project Journal of Management Engineering, 2000, (01): 43-46(in Chinese).

[16]Shi Ying,Liu Jia.Study on Decision-making of Urban Infrastructure Franchising Based on PPP Model. Contemporary Economic Management,2015, (06):18-23(in Chinese).

[17]Sun Guoxiang, Du Jing.Discussion on influencing factors of project return under PPP model. Project Management Technology, 2009, (09): 30-34(in Chinese).

[18]Wang Qian.Study on the Determination of BOT+EPC Project Franchise in Uncertainty.Chongqing Jiaotong University, 2015(in Chinese). 